\title{
LOS INICIOS DE LA CRÍTICA CERVANTINA EN COSTA RICA, EFEMÉRIDES Y VISIÓN ANTROPOLÓGICA
}

\author{
Jorge Chen Sham
}

\section{(c)}

Esta obra está bajo una licencia Creative Commons 



\title{
LOS INICIOS DE LA CRÍTICA CERVANTINA EN COSTA RICA, EFEMÉRIDES Y VISIÓN ANTROPOLÓGICA
}

\author{
THE BEGINNINGS OF CERVANTES' CRITICISM IN COSTA RICA, \\ EPHEMERIS AND ANTHROPOLOGICAL VISION
}

\author{
Jorge Chen Sham
}

\begin{abstract}
RESUMEN
En 1947, por motivo de la celebración del natalicio de Miguel de Cervantes, las Academias Costarricense de la Lengua, y de Geografía e Historia, junto con la Universidad de Costa Rica convocan a sendos homenajes y publican las actas y memorias de sus respectivos eventos durante el año 1948, para unirse a la celebración encomiástica del mundo hispano. Anteriores a esa fecha, no hay publicaciones de tipo erudito según la pesquisa que he realizado. Este trabajo analizará los rasgos filosóficos que se exponen en los dos volúmenes conmemorativos, así como las variables críticas que se ponderan bajo la impronta de la interpretación noventayochista del Quijote, con la importancia de insertar la visión del texto cervantino en la dinámica positivista de "la vida y obra de...".

Palabras clave: Cervantes, García Monge, Fernández Guardia, Bonilla Baldares, Olarte.
\end{abstract}

\begin{abstract}
In 1947, while commemorating Miguel de Cervantes' birth, the Costa-Rican Academy of Language, the Costa-Rican Academy of Geography and History, and the University of Costa Rica invited to pay homage to Miguel de Cervantes, and published, in 1948, the proceedings and transactions of the aforementioned commemoration. In this way, they participated in the Hispanic world celebration of Miguel de Cervantes' anniversary. According to my inquiry, previously there were not, in the Costa-Rican academic medium, learned publications concerning Miguel de Cervantes. This paper will analyze the philosophical features evinced by the 1948 transactions, and the critical variables to ponder under the influence of the Generation of 1898 interpretation of Don Quixote. This paper emphasizes the importance of inserting Don Quixote in the positivistic dynamic of "life and work". Key words: Cervantes, García Monge, Fernández Guardia, Bonilla Baldares, Olarte.
\end{abstract}

\section{Introducción. El rezago del cervantismo en Costa Rica}

La crítica cervantina en Costa Rica ofrece unos rezagos históricos que deben explicarse a la luz del contexto socio-cultural del país y de la conformación de los estudios de literatura en el ámbito nacional. Dentro de lo que se considera como la etapa de las reformas

Dr. Jorge Chen Sham. Universidad de Costa Rica. Escuela de Filología y Lingüística. Costa Rica. Miembro correspondiente de la Academia Nicaragüense de la Lengua y la Academia Norteamericana de la Lengua Española. Correo electrónico: jorgechsh@yahoo.com

Recepción: 06- 06- 2017

Aceptación: 12- 06- 2017 
del estado liberal en las últimas dos últimas décadas del siglo XIX (Quesada-Soto, 1995, pp. 44-45), el cierre de la antigua Universidad de Santo Tomás a cargo del secretario de Educación, don Mauro Fernández Acuña en 1888, deja al país sin unos estudios humanísticos que solamente vinieron a colmarse con la creación de la Universidad de Costa Rica en 1940 (Quesada, 2003, p. 18). Mientras tanto, los gobiernos liberales asumieron la tarea de fortalecer un estado nacional y acometieron la tarea de la modernización de la vida económico-social, material y cultural, con infraestructura de carreteras, hospitales, escuelas y colegios. Todo ello preparaba la consolidación del estado nacional a lo largo de las tres primeras décadas del siglo XX, en el que la urbanización y la modernización del país marcan ese progreso que, en el marco educativo y cultural, acabó en la instalación de teatros, cines, revistas, bibliotecas, tipografías y librerías (Quesada-Soto, 1998, p. 33). El país, entonces, comenzaba a tener una infraestructura y unas instituciones bajo el auge de las agroexportaciones de café y banano, y el fortalecimiento de un proyecto de nacionalismo costarricense con valores axiológicos que polemizaban lo ajeno/lo propio, la tradición/el progreso, el orden/el caos, entre otros (1998, p. 41). Así no es casual que en este contexto se constituyera el 12 de octubre de 1923, la Academia Costarricense de la Lengua, en los salones del Ministerio de Relaciones Exteriores (Chaverri et ál., 2014, p. 104). Se legitima así la concepción de la raza asociada a la cultura y a la lengua, que también se encuentra en las primeras décadas entre los intelectuales costarricenses (Quesada, 2001, p. 231), mientras que en estos años posteriores a su instalación se caracterizan por las escasas reuniones de la Academia, lo cual se agrava tanto por la Guerra Civil como la Segunda Guerra Mundial.

Por otra parte, durante la administración del presidente Rafael Ángel Calderón Guardia (1940-1944), gran estadista y reformador social, se promulga el capítulo de las "Garantías sociales" dentro de la Constitución Política, y se funda, entre muchas instituciones de la vida institucional del país, la Academia de Geografía e Historia de Costa Rica, por Decreto ejecutivo 7, del 10 de julio de 1940; firmado también por el secretario de Educación Pública, Luis Demetrio Tinoco Castro. La primera sesión de la recién fundada academia fue el 10 de agosto. Además, casi dos meses después, el 26 de agosto de 1940, por Ley de la República 362, se crea la Universidad de Costa Rica; también la ley fue refrendada por el señor Tinoco Castro, quien fungió como su rector interino hasta que en el año de 1941 se nombraron oficialmente a las nuevas autoridades de esta casa de estudios, la cual empezó a funcionar en marzo de ese mismo año.

Sirvan estos preliminares histórico-culturales para introducir los inicios de la crítica cervantina en Costa Rica, ya que dentro de una sociología de la recepción literaria, la distinción y el consenso de un texto en el canon crítico, se debe a una tradición de comentarios que se impone bajo un proceso de sacralización (Dubois, 1980, p. 2); eso es cierto, pero cuya legitimación y consumo encuentran su marco de pertinencia dentro de una teoría de las instituciones. Al poner al descubierto cómo funcionan "les roues cachées de la machine littéraire" (Dubois, 1981, p. 3), el análisis de las instituciones literarias se interesa tanto por las carreras de los autores como en la de esos lectores que se posicionan como agentes que intervienen en el campo de las letras, sobre todo cuando estos se transforman en profesores de literatura, miembros de academia, críticos literarios. La pretensión de esta perspectiva teórica es construir con más rigor un objeto, la lectura literaria y las formas de legitimación del texto en un doble movimiento, en cuanto revela lo instituido, descubre lo que instituye y establece (Dubois, 1981, p. 7). 
Los comienzos de la crítica cervantina en Costa Rica descubren la importancia de los procesos de legitimación, así como los códigos de aceptabilidad en los que un a priori, es decir, algo dado de antemano otorga la relevancia y la significación a la crítica literaria. Así, la crítica es una lectura que se configura en un circuito de producción/recepción; se reconoce y se ampara en este marco para que su trabajo sea identificado y funcione como un modo de organización/ distribución del campo de las letras. Véase lo que indican al respecto Altamirano y Sarlo:

\footnotetext{
En realidad lo que llamamos crítica literaria aparece ligado a canales y redes institucionales diferentes, desde el periodismo a la Universidad, pasando por ese órgano típicamente moderno que es la revista literaria. Pero, junto a esta diversidad institucional hay otra diversidad no menos llamativa: bajo la denominación genérica de crítica se reúnen una serie de operaciones discursivas, cuyo lazo común no resulta fácil de identificar. El comentario de un libro en el suplemento literario de un periódico, la biografía de un escritor, la historia de un tema literario, el análisis de un poema, en fin, una amplia gama de objetos y de discursos cae bajo la categoría de crítica o de la labor del crítico. (1983, p. 92)
}

Si la crítica literaria es el lugar de una posición de privilegio y de una perspectiva institucional, una efemérides, el natalicio del Manco de Lepanto reunió en 1947 a las instituciones más reputadas de la vida cultural y educativa del país. La Academia Costarricense de la Lengua realizó una jornada celebratoria, con el objetivo al mismo tiempo de celebrar su reorganización; se trata del Homenaje a don Miguel de Cervantes y Saavedra en el IV centenario de su nacimiento, celebrado el 16 de octubre de $1947^{1}$ (publicado al año siguiente en San José), mientras que la Academia de Geografía e Historia de Costa Rica se le unió a la docta corporación inaugurando de este modo su publicación periódica (Memoria de la Academia de Geografía e Historia de Costa Rica, vol. 1, número 1, 1948). Además, la Universidad de Costa Rica participó de la ocasión, pues realizó entre sus profesores, estudiantes e intelectuales del país, un concurso acerca de Cervantes y su "obra", con el fin de publicar los mejores trabajos en la recién fundada Revista de la Universidad de Costa Rica; se trata del número 3, de junio de 1948. Como vemos, las efemérides cervantinas sirven, con ese prestigio que significa magnificar lo que se denominó la hispanidad universal de la lengua, la raza y la religión, la organización de instituciones culturales, al tiempo que significa posicionarse en el campo cultural costarricense.

\section{Las celebraciones de las academias, la distinción de lo institucional}

Lo anterior se comprueba en la manera en que las aportaciones de estos escritores y hombres de letras se distribuyen en las publicaciones conmemorativas antes citadas. De esta manera, en los volúmenes que publican sendas academias, aparecerán los intelectuales y escritores más representativos de la Costa Rica de la primera mitad del siglo XX. Por ejemplo, Joaquín García Monge (1881-1958), quien no solo se destacó como un narrador fundador de la corriente realista-costumbrista en la literatura nacional, sino también como un "promotor de talentos literarios y director de diversas revistas y suplementos literarios y ediciones de las más importantes en la historia cultural costarricense" (Chacón, 2007, p. 194)², publicó en la Memoria de la Academia de Geografía e Historia de Costa Rica. Su aporte se intitula "Mis contactos personales con Don Quijote" y le interesa destacar y justificar su interés por la figura del personaje a partir de su idealización y el proceso de heroización al que se ha sometido al personaje de ficción. Según García Monge, don Quijote es más relevante por convertirse en un ser "legendario" y "místico" que por su estatuto de personaje literario. Lo anterior obedece al carácter filosófico de la novela cervantina y al conocimiento íntimo que se desprende de 
su figura, pues don Quijote "se va convirtiendo en una expresión simbólica que da lugar a interpretaciones diversas y profundas" (1948, p. 30).

Las opiniones de Joaquín García Monge privilegian el sentido simbólico y profundo de la novela cervantina. Miguel de Unamuno ya había expresado tales ideas en su ensayo "El Caballero de la triste figura; ensayo iconológico", publicado el 1 de noviembre de 1896 en La España Moderna. Se trata de un artículo clave para comprender, en la historia de la recepción cervantina, el desdén que siente el escritor español por los "masoretas cervantinos", incapaces de "penetrar en la eterna sustancia de una obra" (1966a, p. 1228). Él apuesta por una interpretación basada en la intensidad vital y la profundidad filosófica, porque el crítico debe apoyarse, según su opinión, en los pasajes del texto que se presten mejor "para vuelos filosóficos o elevaciones del corazón" (1966a, p. 1232). Unamuno pretende acercarse, entonces, a partir de una profundidad vital y filosófica que él apelará 'quijotismo', con el fin de llegar “a lo verdaderamente eterno y universal” (1966a, p. 1232). Pues bien, García Monge, pondera en su artículo también un acercamiento que revele una forma de vida y de conocimiento intuitivos y lo esboza así: "[a]l Quijotismo hemos de llegar como ejercicio consciente, anhelado, vivo, de filosofía, de educación, de historia" (1948, p. 31), es decir, se trata de una interpretación integrativa y restitutiva que aborde todos los aspectos axiológicos del ser humano, para que la obra esclarezca y nos devuelva "los valores del espíritu" (1948, p. 3). En su ideario cervantino, García Monge comulga con Unamuno, al punto de que, como en su ensayo "El sepulcro de Don Quijote", que puso como prólogo para la segunda edición de su Vida de Don Quijote y Sancho (1914), el quijotismo inspire a nuevos quijotes que saldrán por los valores de la raza y el destino, tal y como asegura Unamuno al final de su exordio: "Ponte en marcha, solo. Todos los demás solitarios irán a tu lado, aunque no los veas. Cada cual creerá ir solo, pero formaréis batallón sagrado: el batallón de la santa e inacabable cruzada" (Unamuno, 1990, p. 153). Mística e ideario identitario se reúnen aquí para que García Monge, el más prestigioso intelectual de la primera mitad del siglo XX, declare también su credo humanístico en la figura de don Quijote.

Por su parte, Ricardo Fernández Guardia (1867-1950), narrador, cronista y diplomático de carrera, representante del purismo en la lengua y con visión extranjerizante respecto del papel de la literatura en cuanto a la recreación de temas europeos y al rechazo del lenguaje vernáculo, hace un recorrido biográfico por los lugares comunes del escritor con el título a secas de "Cervantes" en el Homenaje a don Miguel de Cervantes y Saavedra en el IV centenario de su nacimiento, celebrado el 16 de octubre de 1947, el cual reúne las participaciones que, en el Teatro Nacional, se leyeron ese día. La noción de efemérides cobra todo su sentido de fiesta pública que pondera tanto la "raza" como el legado cultural en la lengua y sus manifestaciones espirituales. Muy propio del positivismo es que la obra de arte manifieste el espíritu y el carácter de su tiempo, pues según enarbola Hipólito Taine en su Filosofía del arte, ella "tiene por objeto manifestar algún carácter esencial o saliente, partiendo de alguna idea importante, más claramente y de una manera más completa de lo que acontece en los objetos reales" (1944, p. 33). Por esa razón, el bosquejo biográfico comienza insistiendo en la virtud del escritor dentro del tópico clásico De viri illustribus, donde los hechos excepcionales y la semblanza verbal se dan la mano (Soria-Ortega, 1981, p. 123).

De esta manera, Fernández Guardia pondera los siguientes rasgos de la biografía cervantina: la valentía con la que peleó contra los turcos, el heroísmo demostrado durante su cautiverio, sus desengaños a la hora de buscar la fama como poeta o como autor de comedias, las penalidades económicas que sufrió en los años trabajados en el erario real, lo cual le costó 
la cárcel. Insiste en el papel de las vicisitudes materiales y espirituales como germen del Quijote, pues se gestó el libro en la cárcel para que le sirviera su propia esposa en el modelo para Dulcinea; encontró en la primera los valores de fidelidad y comprensión que transvasó a su ideal Dulcinea (Fernández-Guardia, 1948, p. 25). Termina este recorrido reafirmando el favor que tuvo de sus contemporáneos la obra, para concluir que la vida del autor ayuda a comprender la "risueña filosofía con que está amasado el Quijote" (1948, p. 26). En tanto ideario vital esta filosofía se dirige hacia dos direcciones: retrata en la novela su propia experiencia y porque, en contacto con el pueblo, "descubre los secretos del corazón humano" (1948, p. 26). De nuevo, quien representa un escritor consagrado en la república de las letras costarricenses se muestra identificado con el pensamiento de Miguel de Unamuno. En plenas celebraciones del III ${ }^{\text {er }}$ centenario de la Primera Parte, el vasco publica un ensayo en abril de 1905 en La España Moderna con el título "Sobre la lectura e interpretación del 'Quijote". Si bien en este artículo Unamuno rechaza toda identificación entre el escritor y su obra de arte, pues el privilegio autoral debilita la afirmación de que el alma del pueblo vive en sus entrañas, Fernández Guardia continúa reafirmando lo que denomina Unamuno "[la] presencia espiritual" de don Quijote, cuya prueba es "su poderosa vitalidad y lo realísimo de su realidad" (1966b, p. 1231).

\section{La crítica universitaria y la literatura como conocimiento}

Como se ha indicado, por aquel entonces la joven Universidad de Costa Rica también se unió al homenaje cervantino y lanzó un concurso cuyos resultados se plasmaron en el número 3 de la Revista de la Universidad de Costa Rica. Llegado a Costa Rica a principios de 1940, el vasco Teodoro Olarte Sáez de Castillo (1908-1980) se inició como profesor de literatura, gramática, literatura en colegios privados y públicos de San José y de Cartago, hasta que en 1956 fue contratado como profesor de tiempo completo en la Universidad de Costa Rica (San Miguel et ál., 2008, p. 46), de manera que cuando colabora en este número de la Revista es un exiliado español que se está abriendo campo y conocimiento en el mundo intelectual del país ${ }^{4}$. Publica en este número de la revista el trabajo "Variaciones filosóficas sobre el 'Quijote", con una dirección bien clara en su línea de acercamiento ensayístico al texto cervantino. Su presupuesto es que una perspectiva filosófica es posible y lanza su tesis desde el inicio de su artículo:

\footnotetext{
La concepción del Quijote es la explicación del último origen de las cosas. Efectivamente, el Quijote responde a esta tremenda cuestión: "Qué es el hombre" [sic]. Su respuesta alcanza las honduras abismales de nuestra naturaleza; por ello se impone una filosofía integral para comprender el Quijote (1948, pp. 204-205)
}

Y esta filosofía comprensiva es para él el existencialismo antropológico, la cual permite "sumergirnos en su valor último" (1948, p. 205). Aquí hay un cambio radical frente a García Monge o Fernández Guardia. Olarte parte de una relación estrecha entre literatura y filosofía para plantear la primera como conocimiento último del ser humano y del mundo, tesis que encuentra su gestación final en el romanticismo, aunque desde siempre la filosofía planteó esta interrogante para que Aristóteles le otorgue su estatuto en la dicotomía historia/ poesía, lo particular/lo universal y se termine apostando por el carácter universal y probable de su imitación, "esclareciendo de este modo la naturaleza profunda de la acción humana y de sus móviles" (Aguiar e Silva, 1979, p. 68). Esta idea medular en su transmisión pasa 
al romanticismo, donde la poesía se concibe como vía ideal del conocimiento de la realidad profunda, "pues el universo aparece poblado de cosas y de formas que, aparentemente inertes y desprovistas de significado, constituyen la presencia simbólica de una realidad misteriosa e invisible" (Aguiar e Silva, 1979, p. 68). Pues bien, tanto Olarte como los ilustres académicos costarricenses de la Lengua pueden sostener esta noción de profundidad simbólica del Quijote: aquella que, en su seminal estudio El Pensamiento de Cervantes (1925), Américo Castro había señalado como débito al romanticismo, pues "vislumbró en la gran novela hondo valor humano y sentido profundo, que se imponía a los tiempos y a las diferencias de gente" (Castro, 1972, p. 15).

Ahora bien, ¿en qué radica su diferencia? En la conceptualización de un sistema filosófico, riguroso y pertinente, que otorgue coherencia a sus planteamientos. La antropología filosófica tiende a centrarse en el problema de la naturaleza del ser humano en el mundo, es "la explicación conceptual de la idea del hombre a partir de la concepción que éste tiene de sí mismo en una fase determinada de su existencia" (P. L. Laudsberg, citado en Ferrater-Mora, 1982, p. 172) y, desde este punto de vista, se trata de una antropología de la comprensión del ser humano, de la reflexión que él realiza para comprenderse a sí mismo. Por lo tanto, su pregunta es siempre circunscrita: ¿qué es la existencia para el ser humano? Nunca es tan general y ambiciosa como ¿qué es la existencia a secas? De esta manera, esta antropología presta atención al ser humano en su devenir, pues para la filosofía de la existencia el ser humano está en el mundo cobrando conciencia de su existencia y preguntándose por el ser, que descubrirá como existencia. En la argumentación que ofrece Olarte, se establece la ecuación, existir=preguntarse por el ser, lo cual conduce a la pregunta por el ser en tanto existencia. Las preguntas por el ser humano y por su existencia son en realidad una única pregunta, para que Olarte proponga a don Quijote y a Sancho Panza como abstracciones de dos tipos de existencia, de modos vitales en cuanto posibilidades y limitaciones humanas.

A la luz de lo anterior, Sancho Panza se presenta en una existencia banal, mientras don Quijote como la existencia que se eleva por encima de la banalidad: Sancho, la existencia inauténtica; don Quijote, la auténtica. Llaman poderosamente la atención las coincidencias de este esquema interpretativo con la teoría del héroe que esboza José Ortega y Gasset en sus Meditaciones del Quijote (1914), pues se trata de un estudio de la estructura de la vida humana en la que Ortega opone la tragedia/la comedia. Y lo plantea así:

\footnotetext{
Héroe es, decía, quien quiere ser él mismo. La raíz de lo heroico hállase, pues, en un acto real de voluntad. [...] De modo que el sujeto trágico no es trágico, y, por tanto, poético, en cuanto hombre de carne y hueso, sino solo en cuanto quiere. La voluntad -ese objeto paradoxal que empieza en la realidad y acaba en lo ideal, pues solo se quiere lo que no es-, es el tema trágico [...]. (1990, pp. 231-232)
}

Sobre la volición y la voluntad funda Ortega su teoría del héroe, de manera que la existencia de Sancho Panza está marcada por la cordura; sus miedos, preocupaciones, alegrías y pesares se hacen comprensibles, indica Olarte, al recurrir al sentido común. Por lo tanto, carece de angustia existencial al rechazar toda percepción de la realidad que no provenga de la evidencia: "la realidad -la de los sentidos- proporciónale suficiente solidez existencial para no angustiarse por la realidad que se halla al otro lado de la vida sensual" (Olarte, 1948, p. 206). En conformidad con la realidad, no necesita Sancho saturar su ideal, menos aún querer y desear, porque sigue la costumbre y lo recibido. Olarte retoma a la inversa los presupuestos del héroe del cual nos habla Ortega en sus Meditaciones: "Tiene en contra suya aquello por negar lo cual es él un héroe: la tradición, lo recibido, lo habitual, los usos de nuestros padres, las costumbres nacionales, lo castizo, la inercia omnímoda, en fin” (Ortega y Gasset, 1990, p. 
237). Por el contrario, Olarte presenta a don Quijote como el hombre angustiado que intenta conducir su existencia hacia "un plano de profundidad y amplitud incomparables" (1948, p. 207), cuando renuncia a la seguridad de lo conocido y decide lanzarse a otra forma de existir. La angustia se valora como un sentimiento positivo en Olarte en la medida en que ella le permite todas las posibilidades humanas, explorar valores inagotables que lo hagan sobrepasar, según Ortega, la inercia y el instinto de conservación (1990, p. 237). Esta "voluntad de ser lo que aún no se es" (Ortega y Gasset, 1990, p. 237) constituye el vértigo en el que debe vivir el héroe. En "El sepulcro de Don Quijote" habla de la locura quijotesca de la siguiente manera Unamuno: "Te consume, mi pobre amigo, una fiebre de océanos insondables y sin riberas, un hambre de universos, y la morriña de la eternidad. Sufres de la razón" (Unamuno, 1990, p. 151). Así, en términos de Olarte, la angustia lo obliga a explorar los límites y a dejar las certidumbres en una coincidencia de ese programa vital llamado 'quijotismo', el cual, indica Olarte, "apunta a lo eterno" (1948, p. 212).

También en el número 3 de la Revista de la Universidad de Costa Rica, publica Abelardo Bonilla Baldares (1898-1969), profesor de derecho y de historia desde los inicios de la Universidad de Costa Rica, miembro de la Comisión redactora del proyecto de Constitución Política de Costa Rica de 1948, destacado político ${ }^{5}$ y filósofo de la historia de la cultura, quien ha pasado a la historiografía nacional por la publicación de la Historia y antología de la literatura costarricense (dos tomos, 1967). En el homenaje universitario, Bonilla participa con un artículo intitulado "Cervantes, el hombre", con el cual reivindica la figura autorial que perfila a los héroes literarios y a su mundo ficcional, para que la obra literaria sea representativa tanto de España como de la entera humanidad. Este doble estatuto de las obras maestras hace que la obra cervantina esté "abierta a especulaciones" (Bonilla, 1948, p. 187); apostando por esa fusión entre el quijotismo del personaje/del libro, cosa que Ortega separaría para ponerse en tesitura distinta a la de Unamuno (Ortega y Gasset, 1990, p. 85). De esta manera, Bonilla busca lo más concreto y humano "que vive en las páginas del libro, que es la vida misma de Cervantes" (1948, p. 189), eso sí, dentro de una perspectiva biográfica. De la visión de mundo, de su posición ante la vida "surge la universalidad de la obra en la profunda significación vital" (1948, pp. 189-190).

La clave sería el propio Cervantes y, como reconocerá Amado Alonso en su "Carta a Alfonso Reyes sobre la estilística", del año 1941, en la que "expone una idea formalista e inmanente de la obra literaria" (Abad, 1997-1998, p. 16), la crítica historiográfica analiza al escritor en su vida y en su tiempo. Esto le permitirá observar "cómo va aumentando el valor concedido a un autor a medida que se le compruebe como un exponente dinámico y como una suma energética de su tiempo" (Alonso, 1969, p. 84). Esto es lo que realiza Abelardo Bonilla cuando aspira, con Américo Castro, a explicar los problemas planteados por Cervantes a la luz de la historia española, pues él posee concepciones peculiares acerca de la vida y su momento histórico, los cuales deben verse desde "el ángulo vital del autor" (Castro, 1972, p. 23). Y cuando atisba los problemas de la España del último tercio del siglo XVI, indica Castro que "Cervantes se halla situado en el centro del problema literario que afecta a la íntima estructura del siglo" (Castro, 1972, p. 27). Al respecto, Américo Castro subraya, en su artículo "La tarea de historiar" $(1964)^{6}$, que "a veces la auténtica realidad de los hechos y de las obras de la historia humana [conducen a] una realidad sólo historiable cuando es puesta en correlación con la estructura humana en que existe, y con los valores en los cuales se hace significante" (citado por Gómez-Martínez, 1972, p. 303). Comprender a España en sus constituyentes pasa 
necesariamente por las grandes obras de la cultura, mientras su descripción y narración deben tomar en cuenta el pensamiento humanístico y de contrarreforma que imperó en la segunda mitad del s. XVI. Su repercusión se encuentra en la ambigüedad y en el relativismo vital que obedece al debate de la preceptiva renacentista entre historia/poesía en el cual sitúase Cervantes:

\begin{abstract}
Lo genial de Cervantes se revela en el arte con que ha introducido en lo más íntimo de la vida de sus héroes el problema teórico que inquietaba a los preceptistas; el autor coloca a Don Quijote en la vertiente poética y Sancho Panza en la histórica. [...] Don Quijote hablará en nombre de la verdad universal y verosímil; Sancho defenderá la verdad sensible y particular (Castro, 1972, pp. 32-33)
\end{abstract}

Bajo este presupuesto, Castro termina exponiendo la tesis del perspectivismo cervantino de la siguiente manera, pues la verdad será "la armonía con el punto de vista de quien la considere" (Castro, 1972, p. 39). Apoyándose en tal correlación entre los hechos humanos y el devenir de una colectividad, Abelardo Bonilla reafirma que Cervantes fue un hombre del Renacimiento, que se empapó del humanismo para resolver las inquietudes estéticas y filosóficas que le exigían tener cuidado y cautela ante la Inquisición, para seguir anclado al ideal renacentista que se cataliza en el tópico de las armas y de las letras, frente a la madurez de miseria y de fracaso en que ha debido vivir, eso sí, en contraste con la aventura de la España imperial, de las armas gloriosas a las que el propio Cervantes aspiró en su vida. Bonilla concluye que, desde el punto de vista de la novela de caballería, la vida explica la obra, para que la incongruencia de una caballería derrotada sea reacción afirmativa: "actúa la razón de un gran ensueño frustrado y, paradójicamente también, una defensa iluminada de su ideal, fundidas ambas en la razón y en la estética propias de una cultura humanista a la española" (1948, p. 193). La coincidencia de esta última afirmación con la propuesta que realizó, en 1926, Ramiro de Maeztu en su "Don Quijote o el amor", no se hace esperar. En el libro Don Quijote, don Juan, la Celestina: ensayos en simpatía, Maeztu reunió un estudio de conjunto sobre las tres más grandes figuras que la literatura española ha ofrecido a la universal. La correlación entre "el valor literario de una obra [y su] valor vital" (Maeztu, 1968, p. 20) depende del paralelismo con que el tiempo biológico del ser humano y la evolución de los pueblos se empaten (Chen, 2001, p. 242), lo cual ocurre para Maeztu cuando el desengaño de la biografía cervantina (Maeztu, 1968, p. 26) permea su novela; sus vicisitudes y desdichas en la Corte, el éxito que buscó como poeta, su prisión y penurias económicas se reflejan en su vida y en su personaje magistral:

\footnotetext{
Cuando Cervantes concibe el "Quijote" no sólo está cansado y desilusionado, sino fracasado y desmoralizado. Y como las fuerzas humanas tienen límite, es inevitable que al escribir su obra anhelase una vida de descanso, como máximo anhelo [...] el recuerdo de su propia vida, de sus ambiciones, de sus sueños y de sus desventuras tiñen todas las páginas del libro. (Maeztu, 1968, p. 40)
}

\title{
4. La literatura como conocimiento y la profundidad del Quijote.
}

En la conformación del cervantismo hispanoamericano, hay que tomar en cuenta que un elenco de sus críticos profesionales o especializados debe esperar hasta la segunda mitad del siglo XX, y ello depende del desarrollo de las carreras de letras y de los circuitos literarios que involucren tanto revistas como editoriales. En el caso de la Costa Rica de la primera mitad del siglo XX y de la aparición de los primeros estudios cervantinos en el país, estos obedecen a hombres de amplia formación y de un mundo intelectual no compartimentado, que Alberto Rodríguez encontró también en el cervantismo cubano hasta 1952, donde sorprendían su 
eclecticismo y la libertad intelectual en sus abordajes críticos (Rodríguez, 2010, p. 12). Para el caso costarricense, hay un paradigma de lectura que se va configurado a partir de 1948, cuando surgen las publicaciones y los primeros críticos costarricenses exponen su comprensión acerca del texto cervantino. La presencia de Miguel de Unamuno es inconfundible en los aciertos de los escritores ya consagrados, tales como Joaquín García Monge o Ricardo Fernández Guardia. Indica Joaquín Ruiz-Jiménez en este sentido:

\begin{abstract}
[...] ningún escritor español de su época había alcanzado el prestigio que consiguió Unamuno. No hay pensador de relieve en Hispanoamérica que, de una forma u otra, no confiese el influjo que para él tuvo el contacto con el rector de Salamanca. Los artículos aparecidos en los diarios y revistas de aquellos pueblos y la riquísima correspondencia [...] demuestran esa presencia viva de Unamuno en la entraña misma de Hispanoamérica. (1970, viii-ix)
\end{abstract}

Esta apreciación general del peso de Unamuno entre los escritores e intelectuales hispanoamericanos de la primera mitad del XX es fundamental; también lo confirma Luis Ferrero en su libro Ensayistas costarricenses, cuando apunta que en el Repertorio Americano escribían tanto Unamuno como Ortega y Gasset (1979, p. 52), lo que explica su atracción y presencia en los artículos que acabamos de referir y de analizar. No cabe duda respecto de la impronta de la Generación del 98 en la conformación de una historia intelectual que aborda su conciencia hispana y quiere emanciparse del yugo norteamericano (Marichal, 1978, p. 83), para repensar el pasado y el futuro de nuestra región en términos de un patrimonio común, ya que "ellos significan la conciencia de nuestra raza por encima de tantas diferencias políticas, económicas y sociales que han incorporado lo mejor de su pensamiento y producción al todo indiviso de la gran civilización hispánica" (de Onís, 1955, p. 21). Revalorar la raza y el destino común dentro de un patrimonio común, como lo es el Quijote, se encuentra en los planteamientos de García Monge hacia una nueva pedagogía "que debe robustecer esta unión espiritual" (Ferrero-Acosta, 1990, p. 40). Por otro lado, se trata de inmunizar a los seres humanos contra inclinaciones materialistas para encontrar mejor su valoración del ser humano; idea en la cual comulgan estos intelectuales, como lo expone con fineza Fernández Guardia.

En cuanto al desarrollo de la Universidad de Costa Rica, ella vino a estimular la ciencia y la cultura en el país, así como la ascensión de los intelectuales hacia posiciones de dirección en la vida nacional. Al amparo de la Universidad, llegaron profesores extranjeros y se organizaron las carreras y facultades. En la Facultad de Filosofía y Letras comenzaron a impartirse los estudios superiores de filología el 7 de marzo de 1941. Incide en la constitución de la literatura en cuanto saber organizado y sistemático y en la preparación de docentes e investigadores en estos campos; por ejemplo, véase lo que explica Constantino Láscaris Comneno en el ámbito de la filosofía e historia de las ideas:

Como característica global -y extendible [sic] a otros niveles docentes y a la reciente Universidad [...]- el desarrollo y la calidad de los libros e investigaciones de Filosofía, en los últimos diez años (a partir de 1950), superó lo publicado en los ciento cincuenta años anteriores (Láscaris, 1983, p. 474)

Su desarrollo se hizo ingente con la aparición de la Revista de la Universidad de Costa Rica (1957). También de la misma opinión acerca del papel de la recién fundada casa de estudios superiores es Abelardo Bonilla, quien destaca el estímulo del género ensayístico y la conformación de opinión crítica, pues "por la obra y por la influencia de la Universidad, el ensayo ha adquirido un desarrollo extraordinario y abarca la labor de investigación científica, la crítica sociológica, política y artística, la interpretación histórica” (Bonilla, 1981, p. 251). Así, jóvenes profesores como el mismo Bonilla o el exilado Olarte vienen a engrosar las filas 
de los cuadros docentes de la Universidad de Costa Rica e inauguran, propiamente hablando, la crítica cervantina en Costa Rica, planteando ese principio de profundidad que Ortega y Gasset expuso con tanto denuedo en sus Meditaciones del Quijote. Valorar la obra en su justa dimensión espiritual e histórica implica, para Bonilla o para Olarte, que detrás de esos símbolos vitales y filosóficos se esconde una interpretación que revela un amplio margen de indeterminación. Ellos tienden a universalizar las vivencias del texto y dan lugar a mecanismos de reconocimiento/identificación muy propios de una lectura antropológica y trascendental del Quijote (Chen, 1989, p. 117). Tal interpretación no escapa de un universalismo del texto cervantino que habla por igual a todas las épocas y a todas las culturas, con lo cual se consagra un modelo de lectura que posee, como contrapartida, la emergencia de un discurso identitario con rasgos "metafísicos" para Costa Rica, según lo analizado con pertinencia por Alexander Jiménez M. Este procura "la articulación de circunstancias, procesos, y movimientos complejos" (2005, p. 69), bajo una comprensión que no solo se olvida de las determinaciones sociohistóricas, sino que también vuelve sobre el carácter colectivo de realidades inmutables tales como el lenguaje y la literatura en tanto expresión del "alma" nacional".

\section{Notas}

1. Solamente se realizó una reunión ordinaria el 23 de agosto de 1947, de manera que el homenaje a Cervantes significó una ocasión especial; por otra parte, "hay constancia de la poca actividad durante los años siguientes" (Chaverri et ál., p. 111), de manera que esta tiene una significación especial en la vida de la Academia.

2. $\quad$ Entre sus obras se destaca el Repertorio Americano, de vocación continental y en la que publicó lo más granado de la intelectualidad hispanoamericana y española. La Real Academia Española nombró a García Monge como miembro correspondiente por Costa Rica en 1922, con el fin de crear la costarricense el año siguiente. Se trata de apuntar algunos rasgos significativos desde el punto de vista institucional.

3. Lo publicó primeramente en La España Moderna, en febrero de 1906.

4. Es más, como nunca pudo presentar su tesis en España porque sale al exilio, presenta su tesis de grado en filosofía en 1945 ante la Facultad de Filosofía y Letras.

5. Fue diputado propietario por la provincia de San José (1949-1963), vicepresidente de la República (19581962) y miembro de número de la Academia Costarricense de la Lengua, a partir de 1955.

6. Artículo que resume retrospectivamente su proyecto historiográfico, por cierto.

7. Esto no puede analizarse detalladamente en este artículo, pues sobrepasa sus límites de pertinencia.

\section{Bibliografía}

Abad, F. (1997-1998). Tesis de Amado Alonso. Cauce, Revista de Filología y su Didáctica. 20-21, 9-21.

Aguiar e Silva, V. M. (1979). Teoría de la literatura. Madrid: Gredos.

Alonso, A. (1969). Materia y forma en poesía. (3 ed.). Madrid: Gredos.

Altamirano, C. y Sarlo, B. (1983). Literatura y sociedad. Buenos Aires: Hachette.

Bonilla-Baldares, A. (1948). Cervantes, el hombre. Revista de la Universidad de Costa Rica. 3, 187.

Bonilla-Baldares, A. (1981). Historia de la literatura costarricense. (3 ed.). San José: Stvdium.

Castro, A. (1972). El pensamiento de Cervantes. Barcelona: Noguer. 
Chacón, A. (Coord.). (2007). Diccionario de literatura centroamericana. Heredia: Universidad Nacional de Costa Rica.

Chaverri, A. et ál. (2014). Memoria, Academia Costarricense de la Lengua (1923-2013). San José: SIEDIN-Universidad de Costa Rica.

Chen Sham, J. (1989). El Quijote y su lectura: el discurso de la crítica costarricense (19401986). Imprévue. 1, 89-128.

Chen Sham, J. (2001). El "amor intellectualis" orteguiano y la interpretación cervantina de Ramiro de Maeztu. Estudios Humanísticos, Filología. 3, 237-249.

Dubois, J. (1980). Sociologie des textes littéraires. La Pensée. 215, 1-7.

Dubois, J. (1981). Introduction. Littérature (consagrado a las instituciones literarias). 44, 3-14.

Fernández-Guardia, R. (1948). Cervantes. Homenaje a don Miguel de Cervantes y Saavedra en el IV centenario de su nacimiento, celebrado el 16 de octubre de 1947. San José: Imprenta Nacional.

Ferrater-Mora, J. (1982). Diccionario de filosofía. Tomo I. Madrid: Alianza Editorial.

Ferrero-Acosta, L. (1979). Ensayistas costarricenses. San José: Lehmann.

Ferrero-Acosta, L. (1990). La clara voz de Joaquín García Monge. (3 ed.). San José: Editorial Costa Rica.

García-Monge, J. (1948). Mis contactos personales con Don Quijote. Memoria de la Academia de Geografía e Historia de Costa Rica. 1, 30.

Gómez-Martínez, J. L. (1972). Américo Castro y Sánchez Albornoz: Dos posiciones ante el origen de los españoles. Nueva Revista de Filología Hispánica. 21.2, 289-310.

Jiménez-Matarrita, A. (2005). El imposible país de los filósofos. San José: Universidad de Costa Rica.

Láscaris, C. (1983). Desarrollo de las ideas filosóficas en Costa Rica. (3 ed.). San José: Stvdium.

Maeztu, R. (1968). Don Quijote, don Juan, la Celestina: ensayos en simpatía. (10 ed.). Madrid: Espasa-Calpe.

Marichal, J. (1978). Cuatro fases de la historia intelectual latinoamericana (1810-1970). Madrid: Fundación Juan March/Cátedra.

Olarte Sáez del Castillo, T. (1948). Variaciones filosóficas sobre el "Quijote”. Revista de la Universidad de Costa Rica. 3, 204-205.

Onís, F. (1955). España en América: Estudios, ensayos y discursos sobre temas españoles e hispanoamericanos. Madrid: Cultura Hispánica/Universidad de Puerto Rico.

Ortega y Gasset, J. (1990). Meditaciones del Quijote. Madrid: Cátedra.

Quesada, J. R. (2001). Historia de la historiografía costarricense, 1821-1940. San José: Universidad de Costa Rica.

Quesada, J. R. (2003). Estado y educación en Costa Rica: Del agotamiento del liberalismo al inicio del Estado interventor: 1914-1949. San José: Universidad de Costa Rica. 
Quesada-Soto, Á. (1995). La formación de la narrativa costarricense (1890-1910): Enfoque histórico-social. San José: Universidad de Costa Rica.

Quesada-Soto, Á. (1998). Uno y los otros: Identidad y literatura en Costa Rica, 1890-1940. San José: Universidad de Costa Rica.

Rodríguez, A. (2010). Cervantes y Cuba: aspectos de una tradición literaria. Newark: Juan de la Cuesta.

Ruiz-Jiménez, J. (1970). Unamuno y América. (2 ed.). Madrid: Cultura Hispánica.

San Miguel, M. L. et ál. (2008). Teodoro Olarte Sáez del Castillo: Antropología Filosófica y Cultura Personal. Vitoria-Gasteiz: Ayuntamiento.

Soria-Ortega, A. (1981). Sobre el biografismo de la época clásica: Francisco Pacheco y Paulo Jovio. 1616, Anuario de la Sociedad Española de Literatura General y Comparada. 4, 123-143.

Taine, H. (1944). Filosofía del arte. México, D. F.: Nueva España.

Unamuno, M. (1966a). El Caballero de la Triste Figura: ensayo iconológico. Obras completas. Tomo I. (1227-1230). Madrid: Editorial Escelicer.

Unamuno, M. (1966b). Sobre la lectura e interpretación del Quijote. Obras completas. Tomo I. (1231-1233). Madrid: Editorial Escelicer.

Unamuno, M. (1990). Vida de Don Quijote y Sancho. México, D. F.: REI. 